\title{
How we talk about "Pot" matters: strategies for improved cannabis risk communication
}

\author{
Leela Steiner*, Anne-Marie Nicol, Angela Eykelbosh
}

\section{Introduction}

Canada's Bill-C45, also known as the Cannabis Act, legalized the production, distribution, and possession of cannabis on 17 October 2018. Canadians can now purchase and possess up to $30 \mathrm{~g}$ of dried cannabis or its equivalent and share this amount with other adults, defined as those older than 18 or 19 depending on the province. One gram of dried cannabis is equal to $5 \mathrm{~g}$ of fresh cannabis, $15 \mathrm{~g}$ of edible product, $70 \mathrm{~g}$ of liquid product, $0.25 \mathrm{~g}$ of concentrates (solid or liquid), or 1 cannabis plant seed.

This legislation is a shift in the legal landscape and brings with it a host of challenges for municipalities, provinces, law enforcement agencies, emergency services, and perhaps most crucially for public health organizations and professionals. Foremost among the challenges for public health is crafting effective and consistent risk messages. This is confounded by the paucity of clear evidence regarding risks from short- and long-term cannabis use across a wide variety of populations.

Developing cannabis communication strategies should involve several key elements. First, as public health professionals, we need to use plain, targeted language to adequately and fairly inform users of what is currently known about the risks to themselves and others. Second, we need to structure our messages in ways that can help reduce harms for those who choose to use cannabis. Third, we need to conscientiously avoid relying on stereotypes, stigma, and fear when presenting information on cannabis to the public. These elements speak to risk communication basics that often take the form of "be first, be right, and be credible".

While these tenets are applicable to a host of public health issues, cannabis brings with it a unique history of prohibition in Canada and the United States. This commentary will focus on the conversations public health should be having around cannabis in light of an evolving legal framework and new evidence that will arise as research on cannabis use grows. The first section will discuss cannabis terminology, its history, and how we can choose words that support public health priorities. The next section will outline the limits of current evidence and how we can craft messages when many answers remain unknown. This is followed by a discussion on finding the balance between stigmatization and normalization, and an overview of communication approaches that help ensure that all users understand their legal responsibilities and existing criminal offences.

*Corresponding author: Leela Steiner (email: Leela.Steiner@bccdc.ca)

\section{Getting the terminology right}

Though cannabis use, generally noted as originating in Asia, has a rich global history that is tied up with colonialism, early international trade, and military interventions, ${ }^{1}$ its spread to the United States began in the early 1910 s with large numbers of Mexican and other Latin American immigrants fleeing the violence of their own revolutions (Warf, 2014). Early prejudices against cannabis have been characterized as "thinly veiled racist fears of its smokers", (Warf, 2014) such that aggressive anti-cannabis government campaigns made a deliberate shift to the term marijuana, the Spanish name for cannabis (sometimes spelled marihuana), in an attempt to conjure images of a dangerous foreign presence. Similarly, Mexican immigrants were frequently blamed for criminal activity as a result of their "marijuana" use and these campaigns promoted stories about "innocent" citizens under the influence of cannabis engaging in crime, sexual violence, insane behaviour, and murderous sprees (Warf, 2014). Propaganda films such as "Reefer Madness" (1936) solidified these efforts and portrayed marijuana as destroying the lives of teenagers, leading them to commit murder and rape (Meade et al., 1936). The racist rebranding of cannabis use and users became a powerful tool of prohibition and has had long-lasting effects on how we talk about and perceive cannabis in the United States and Canada.

Marijuana is not the only term that has taken root in North American culture, both in media and in mainstream conversation. "Pot" became shorthand for the Mexican influence on American citizens; it is an abbreviation of "potación de guaya" or "drink of grief", a mixed beverage that contains soaked cannabis seeds in guava wine or brandy (Goode, 1970). In Southeast Asia, cannabis was widely known by the Sanskrit word "ganjha" as it had spiritual connotations with the god Ganga (Bennett et al., 1995). However, it was not until the plant was brought by Indian workers to Barbados and Jamaica that the term became associated up with the use of rum, such that it took on implicit associations with the cycle of work, debt, and poverty present on the sugar plantations of those regions (Angrosino, 2003). The term "weed" grew out of this stereotype, as cannabis was decried by missionaries in the region as a "vile weed" that was responsible for increased crime (Warf, 2014). Since the mid20th century, numerous other slang terms (e.g., dope, grass, gas, 420, dagga, skunk, etc.) have taken hold in different regions and communities.

${ }^{1}$ See Warf (2014) for a detailed history of the global geographies of cannabis use. 
Rather than attempting to incorporate slang terminology into public health risk communication, practitioners have an opportunity to both distinguish and clarify their message by employing more formal terminology. The most apt term is likely to be its genus name, Cannabis. In 1753, Carl Linneaus named the two most common species of cannabis, Cannabis sativa $L$. and Cannabis indica. Although debate remains regarding the taxonomy and nomenclature of other species (C. ruderalis) and sub-species (hemp) belonging to this genus (Small, 2015), the use of cannabis has two clear advantages in risk communication. First, using formal terminology rather than terms linked to harmful stereotypes helps to reduce the stigma associated with cannabis use. Second, using formal terminology emphasizes the regulatory aspect rather than a user-based or promotional approach (Box 1).

\section{Box 1. Terminology}

Getting the terminology of cannabis communications right also goes beyond the word used to describe the plant. Indeed, many of the colloquialisms associated with cannabis use may hinder the ability of public health to address serious health concerns. For example, we can move from the term "smoke" which ignores a growing number of routes of consumption (such as the use of edibles, lotions, beverages, and oils) and instead choose the more generic "use". Instead of using the term "recreational cannabis" to distinguish from medical cannabis, it may be useful to use the term "commercial cannabis". This not only emphasizes the business interests involved in producing and marketing cannabis, but it avoids overtly promoting cannabis as a leisure activity. Many educational campaigns currently use the phrase "driving high" which connotes a sense of fun and adventure. In contrast, "driving impaired" better aligns with messaging on alcohol impairment and its similarly serious legal consequences. Finally, news media as well as government agencies have tended to refer to sale locations as "dispensaries", which implies a quasi-medical (rather than profit-driven) mission and (or) a promise of beneficial or therapeutic effects, regardless of whether these are supported by medical science. It may be more balanced to use the term "retail outlet" which expresses the reality that in most cases, these stores are commercial, for-profit, enterprises serving both medical and nonmedical users.

Terminology is important. It is clear at this point in the evolution of Canadian legalization that the promotion and advertising of cannabis will be strictly regulated. If public health uses the right words, we can craft messages that signal priorities relevant to the mandate of Canadian cannabis legislation and reflect the nature of cannabis as a controlled substance rather than as a casual product. This provides public health organizations and professionals with an opportunity to support their own goals, rather than doing the work of the cannabis industry for them and promoting a product without a balance of risk attached.

\section{Understanding the limits of evidence}

Credibility is key in any public health campaign. However, credible messaging around cannabis is complicated by a number of factors, not the least of which is the memory of false or harmful public health claims made during prohibition, and the perception that today's public health professionals may still suffer from "reefer hysteria" to some extent and a bias towards overemphasizing risks (Canadian Centre on Substance Abuse, 2017, p.21). More importantly, cannabis is associated with numerous unsubstantiated health claims. Although there is growing evidence to support the use of cannabis for specific medical conditions (National Academies of Sciences Engineering and Medicine, 2017), we remain far from a comprehensive understanding of its therapeutic benefits or adverse effects over the short or long term. Mostly, this is a function of the difficulty of study. Until now, simply being illegal has made it quite challenging to conduct clinical or population-level research on these issues.

Although legalization will facilitate research and (in time) enhance evidence-based decision-making, the current challenge for public health practitioners is to adequately and rationally inform the public in the face of large uncertainties and perhaps some degree of skepticism.

One key strategy is to acknowledge that our understanding of health impacts is incomplete and that there are limits to the evidence we currently have. As Covello and Sandman (2001) explained, recognizing and acknowledging unknowns and uncertainties are important hallmarks for maintaining credibility and trust with the public. Public health will do a great disservice to future communication efforts if claims are made that cannot be supported by evidence. As public health professionals interacting with the public, it is far better to err towards admitting to not having answers than stretching the research and being "wrong" in the eyes of the audience. Recognizing unknowns also allows for timely updates when evidence is finally generated. Indeed, acknowledging uncertainty increases the likelihood that people will pay attention and trust future messaging.

A second strategy is to focus on public health impacts that transcend cannabis legalization and are known to have a large public health impact. For example, smoking is bad for one's health, regardless of what is being smoked. It is well established that inhaling particulates and polycyclic aromatic hydrocarbons has long-term deleterious effects on the lungs and will negatively impact overall health (Cao et al., 2016; Kim et al., 2013; Lovecchio and Heise, 2015; National Academies of Sciences Engineering and Medicine, 2017). A second example is the potential for poisonings. As with any other substance, medicinal or not, consuming too much cannabis has adverse consequences, as evidenced by the rising number of cannabis poisonings documented by poison control centres (Wang et al., 2014). Finally, driving while impaired is a dangerous activity (again, regardless of why the driver is impaired). Although much additional work is required to understand the more specific positive and negative effects of cannabis on human health, focusing on these basic truths may help to avoid a large proportion of the mortality and morbidity associated with increased cannabis use (if use increases with legalization). 
We can make a concerted effort to use research that employs systematic and transparent approaches when presenting evidence. The National Academies of Sciences, Engineering and Medicine (2017) published one such document entitled "The Health Effects of Cannabis and Cannabinoids". This review uses a strength-of-evidence approach; that is, it rates existing health evidence on the effects of cannabinoids in different contexts as insufficient, limited, moderate, substantial, or conclusive. This type of work emphasizes that, as with any other medicine, cannabis may be "good" for some things but not for others, and that it is neither a cure-all nor a "harmless" natural remedy. Introducing the public to this more nuanced, contextualized view of cannabis use will not only promote more a cautious approach to cannabis use, but also serve to remove associated stigma.

\section{Neither stigmatization nor normalization}

The Chief Medical Officers of Health of Canada and the Urban Public Health Network recently produced a report on public health perspectives related to cannabis policy and regulation (Chief Medical Officers of Health Canada and Urban Public Health Network, 2016). The purpose of the paper was to provide expert advice from a public health perspective on plans to legalize cannabis (which was published before Bill C- 45 came into effect). Among their many recommendations, they emphasized the critical challenge of neither stigmatizing cannabis use (which drives people to avoid health care or treatment) nor normalizing its use, given that we suspect it can have serious health consequences for some individuals.

This approach is shown in Figure 1 adapted from Marks' The Paradox of Prohibition (1993) and an adapted version is discussed at length in the Chief Medical Officers of Health Canada and the Urban Public Health Network report (2016). Figure 1 illustrates that there is a "sweet spot" of sorts, at which the harms associated with rigid control of a substance (social stigma, criminal convictions, lack of access to treatment) are minimized as

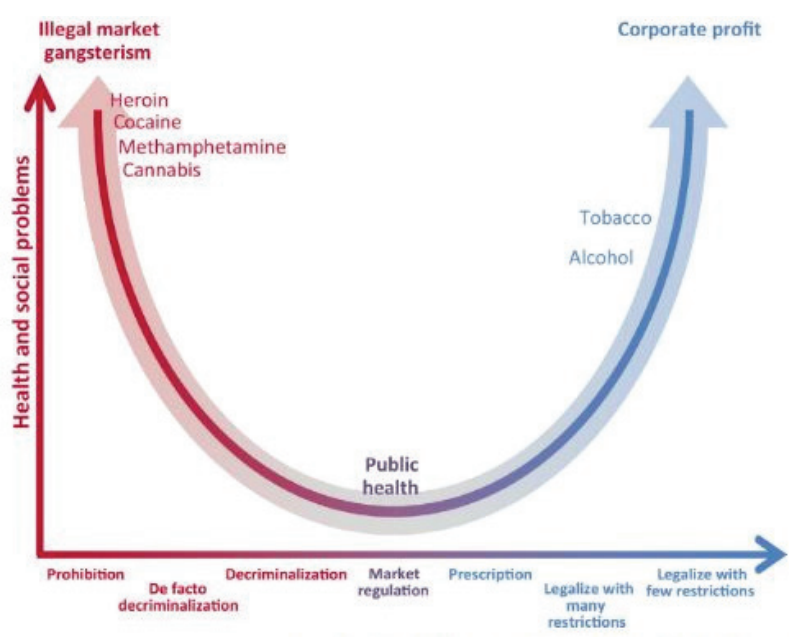

Figure 1. "The Paradox of Prohibition" adapted from Marks (1993). Reproduced with permission from the Canadian Drug Policy Coalition. are the potential harms of a completely uncontrolled, commercially driven market in which substance use increases despite deleterious effects.

As shown in Figure 1, health and social harms may be similar in magnitude under either prohibition or total legalization. Further, those harms can never be fully eliminated, only minimized through responsible public health regulation focused on harm reduction.

\section{Limit or reduce harm for new and established users}

In the 1990s, Canadian public health officials began searching for alternatives to drug enforcement in the wake of the HIV/ AIDS crisis (Giffen et al., 1992). What began as a bottom-up movement that focused on promoting health and mitigating harm to individuals (as well as a platform for more structural social change) (Roe, 2005) has transformed into top-down government policy that seeks to "accept that drug-taking cannot be prevented, and instead [to] concentrate on reducing its consequences for health and crime"(Reporter, 2003).

Public health now has a golden opportunity to apply these principles to mitigate the risks of cannabis use. For new users, we can focus education campaigns on the diversity and potencies of the products available (both in the legal market, and those sold illicitly). This includes messaging around edibles, which are likely to create increased poisoning risks due to their high potency (Steigerwald et al., 2018). One component of harm reduction for new users may therefore include making low-potency products available. For established users, we can focus on trying to improve habits and reduce risky behaviours. For example, the use of filters for smoked cannabis reduces the quantity of contaminants passed directly to the lungs (Sullivan et al., 2013). Similarly, public health professionals may want to discourage the use of cannabis via smoking and point people to less harmful routes of consumption.

For all users, a critical component of harm reduction should include the provision of easy-to-access information on consumption and, in the case of problems, treatment options (such as tools and resources for cannabis use disorder). Public health organizations can also act as a source of guidance on growing, using, and storing products in the home with the aim of mitigating accidental poisonings and exacerbating known environmental hazards in the home (e.g. mould and indoor pesticide use). ${ }^{2}$ Similarly, these organizations can promote the use of poison control centres for accidental poisonings or other adverse events with the intention of reducing the stigma around use. These practices can be as simple as including local poison control centre telephone numbers on every cannabis product label or as broad as wide-scale public education campaigns (Box 2).

\footnotetext{
${ }^{2} \mathrm{~A}$ more detailed outline of these environmental health risks as well as ways to reduce them are presented in a National Collaborating Centre for Environmental Health (NCCEH) evidence review Growing at Home: Health and Safety Concerns for Personal Cannabis Cultivation (Eykelbosh and Steiner, 2018) and an accompanying factsheet (Steiner, 2018).
} 


\section{Box 2. Guidance rather than prohibition}

Canada’s Lower-Risk Cannabis Use Guidelines (Fischer et al., 2017) were developed in partnership with addiction and health experts (and endorsed by a number of key Canadian public health organizations) and provide evidence-based recommendations on how public health entities can promote lower-risk behaviours among cannabis users. The intervention tools inform users of choices that will improve their health and that are feasible under emerging legalization regimes in Canada. Ten major recommendations were developed and include choosing low-potency tetrahydrocannabinol (THC) products, avoiding combusted cannabis, and using nonsmoking methods, as well as avoiding deep or other risky inhalation practices (Fischer et al., 2017). The report on these guidelines also highlights how prohibition has largely been ineffective when it comes to cannabis use and that the harms associated with cannabis can be influenced by behavioural choice. Expert assessment has consistently concluded that interventions that modify these behaviours rather than discourage use altogether can lead to improved public health outcomes (Fischer et al., 2017).

\section{Ensure that all users understand legal responsibilities and new criminal offenses}

Three main objectives have anchored the Cannabis Act (Government of Canada, 2018) through the legalization process:

1. Reducing cannabis availability for youth;

2. Limiting revenues for criminal activity; and

3. Protecting public health and safety by supporting regulated access for adults.

Part of this mandate includes avoiding the criminalization of cannabis users, including youth. But that goal is only attainable if the public is comprehensively educated about their new responsibilities and the new criminal offences related to cannabis legalization; communicating these pieces of information is complex, in part because of the different regulations emerging in different jurisdictions.
According to the Act (Canada Department of Justice), the federal government will be responsible for regulating and enforcing industry-wide standards for commercial producers, while the territories and provinces will be responsible for overseeing the distribution and sale of cannabis as well as developing guidelines and rules for growing cannabis at home. Municipalities will also take on some of the responsibility; they will likely oversee local land use regulations, business licensing, and the regulation of public consumption spaces and personal cultivation.

Laws and penalties around smoking are one issue that has generated a range of responses from the authorities and will require diligence when it comes to communicating legal responsibilities for users. For example, knowing where it is legal to use cannabis will be a challenge, particularly as this will vary by municipality, and even by institution, in some provinces. Across Canada, different levels of government are developing signs to indicate where cannabis can be used, with a range of approaches (see Figure 2). Some use a stylized cannabis leaf and others use representations of rolled cannabis cigarettes or vaporizers, with variances in whether the signs suggest that people can (a green circle) or cannot (a red circle with a line through) use the product in that area. These variations may cause challenges, particularly for those who travel and wish to consume in other provinces (Box 3 ).

\section{Box 3. Targeted Programs}

Washington State uses a program that focuses on communicating with youth through parental relationships. With the goal of addressing underage cannabis use, the "Start Talking Now" program emphasizes that parents can act as a positive influence in youth behaviour if they address the issue of cannabis use in a genuine, thoughtful manner (one that is underpinned with resources on state policies and laws and information on healthy choices) (StartTalkingNow.org). Oregon, conversely, has focused a great deal of effort on helping users become informed about their legal responsibilities; their program "Educate Before You Recreate" highlights rules around selling, buying, and possession (Whatslegaloregon.com, 2018).

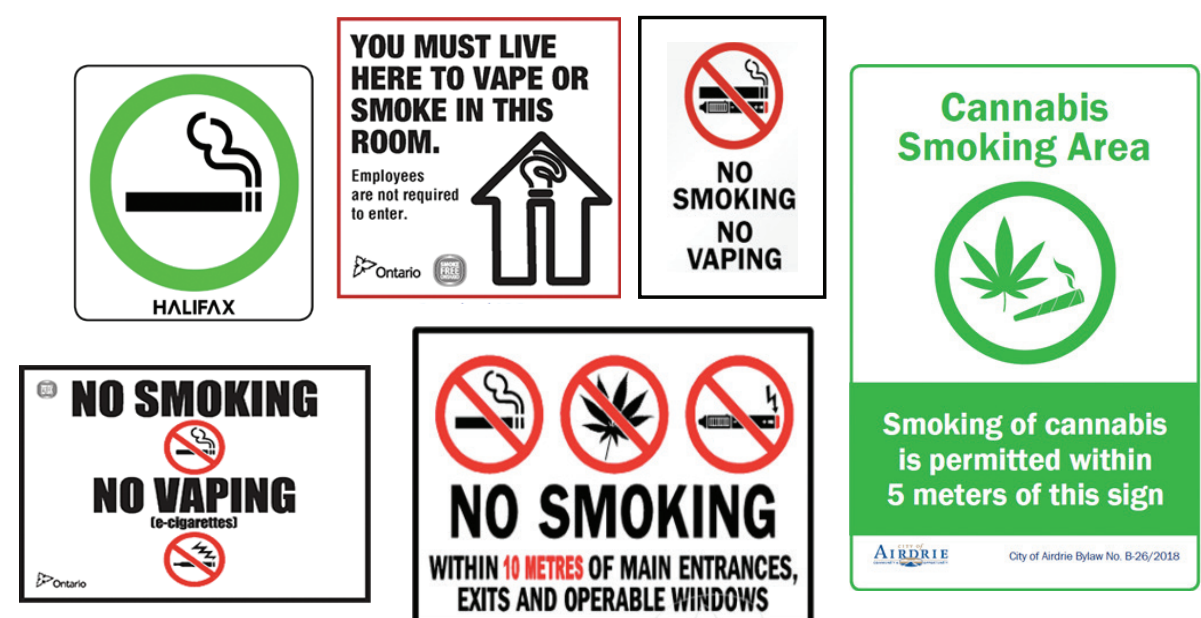

Figure 2. Examples of Canadian signage for cannabis consumption regulations (City of Airdrie; City of Edmonton; City of Halifax; Ontario Ministry of Health and Long-term Care; Regional Municipality of Wood Buffalo). 
One other important group that requires specific risk messaging is tourists. Cannabis tourism is well established in the US states where it has been legalized. Indeed, a Colorado review found Cannabis tourism rose $51 \%$ in that state since legalization and generated US \$6.5 million in revenue in 2016 (Orens et al., 2018). Tourists need clear messaging about what they can purchase as well as where and how they can use what they have bought. Colorado research also found a significant rise in the number of out-of-state admissions to emergency rooms for cannabis-related use after legalization in that state (Kim et al., 2016). Given the inconsistent policies and bylaws about where and how people can use cannabis across Canada, developing messaging specifically for tourists and including information on what to do in the event of over use when you are a foreigner, is warranted.

\section{Takeaways}

A broad spectrum of messages must be conveyed as cannabis legalization unfolds in Canada. At first pass, the public health role seems clear: communicate the potential health impacts of cannabis use. While this is critical, the process is impeded by a limited evidence base and tainted by a history of overemphasizing negative associations for nonhealth related reasons. To grapple with these challenges, public health professionals need to carefully apply tools used for other exposures and conduct critical assessments of new data to craft messages that reflect where we are today in terms of our scientific understanding of the impacts of cannabis on health.

However, public health has a much broader role when it comes to communicating with the public about legal cannabis. As described above, conversations about where it is appropriate and legal to use as well as education regarding the impacts of growing plants indoors also fall within the mandate of public health. Consistency in messaging and how to effectively disseminate these messages (e.g., using standardized symbols that everyone understands) is going to be an essential component of this process. Considering impacts that extend beyond the user, such as accidental consumption or poisoning in children or pets, also falls under the mandate of public health. We need to start talking about these issues proactively, as better education may help reduce these types of impacts.

Attention to how we craft these messages is important too, ensuring that the language of public health messaging reflects the gravity of this newly legalized, controlled substance. Messaging also needs to be inclusive of new users and those unfamiliar with our laws who may come to Canada to experience our legal cannabis system. Cannabis use is serious and our response to it should emphasize concepts such as "low and slow" and the principles of harm reduction that are encompassed by messaging used for similar products, such as alcohol and tobacco.

Finally, public health professionals can become engaged with this issue by educating themselves about cannabis, keeping up to date on the evidence base as it evolves, and talking about cannabis across a spectrum of applications. Being first, right, and credible will keep the public oriented towards public health messaging rather than to cannabis industry messaging — which has the potential to increase risks rather than prevent harm. There is a lot to say about cannabis, and public health has an opportunity to reframe and redirect a conversation that has just gotten started.

\section{Acknowledgments}

Production of this document has been made possible through a financial contribution from the Public Health Agency of Canada through the National Collaborating Centre for Environmental Health. The authors would like to thank Michele Wiens, Information Specialist (NCCEH) for her inputs and edits; Lydia Ma, Manager, National Collaborating Centre of Environmental Health (NCCEH) for her input and edits; Jill Iverson, Team Leader, Corporate Communications (City of Airdrie) for her assistance with signage information; and Emily Rees, Program Coordinator at the Canadian Drug Policy Coalition (Centre for Applied Research in Mental Health and Addiction, Simon Fraser University) for figure permissions.

\section{References}

Angrosino, M. V. 2003. Rum and ganja: Indenture, drug foods, labor motivation, and the evolution of the modern sugar industry in Trinidad. In W. R. Jankowiak and D. Bradburd (eds.) Drugs, labor, and colonial expansion. Tucson, AZ: University of Arizona Press.

Bennett, C., Osburn, L., and Osburn, J. 1995. Green gold the tree of life: Marijuana in magic \& religion. Frazier Park, CA: Access Unlimited.

Canada Department of Justice. Cannabis legalization and regulation. [Online] Available at: https://www.justice.gc.ca/eng/cj-jp/ cannabis/ [accessed 9 Jan. 2019].

Canadian Centre on Substance Abuse. 2017. Canadian youth perceptions on Cannabis. Otttawa, ON: Canadian Centre on Substance Abuse. Available at: http://www.ccsa.ca/Resource\%20 Library/CCSA-Canadian-Youth-Perceptions-on-Cannabis-Report2017-en.pdf [accessed 18 Jan. 2019].

Cao, D., Srisuma, S., Bronstein, A.C., and Hoyte, C.O. 2016. Characterization of edible marijuana product exposures reported to United States poison centers. Clin Toxicol (Phila). 54(9): 840-846. doi: 10.1080/15563650.2016.1209761

Chief Medical Officers of Health Canada, \& Urban Public Health Network. 2016. Public health perspectives on cannabis policy and regulation. Saskatoon, SK: Urban Public Health Network. Available at: http://uphn.ca/wp-content/uploads/2016/10/ Chief-MOH-UPHN-Cannabis-Perspectives-Final-Sept-262016.pdf [accessed 18 Jan. 2019].

City of Airdrie. Cannabis [cannabis smoking area sign]. [Online] Available at: https://www.airdrie.ca/index.cfm?serviceID =1413 [accessed 18 Jan. 2019].

City of Edmonton. Edmonton's cannabis rules [cannabis no smoking sign]. [Online] Available at: https://www.edmonton.ca/city_ government/edmonton-s-cannabis-rules.aspx [accessed 18 Jan. 2019].

City of Halifax. Cannabis and smoking in Halifax [smoking sign]. [Online] Available at: https://www.halifax.ca/city-hall/legislationby-laws/by-law-standards/cannabis-smoking-halifax [accessed 18 Jan. 2019]. 
Covello, V., and Sandman, P. 2001. Risk communication: Evolution and revolution. 164-178 in A. Wolbarst (ed.) Solutions to an environment in peril. Baltimore, MD: John Hopkins University Press.

Eykelbosh, A., and Steiner, L. 2018. Growing at home: Health and safety concerns for personal cannabis cultivation. Vancouver, BC: National Collaborating Centre for Environmental Health. Available at: http://www.ncceh.ca/documents/evidence-review/ growing-home-health-and-safety-concerns-personal-cannabiscultivation?utm_source $=$ Cyberimpact\&utm_medium $=$ email\&utm campaign $=$ NCCEH-eNews---March-2018 [accessed 18 Jan 2019].

Fischer, B., Russell, C., Sabioni, P., Brink, W. v. d., Foll, B. L., Hall, W., Rehm, J., and Room, R. 2017. Lower-risk cannabis use guidelines: A comprehensive update of evidence and recommendations. Am J Public Health. 107(8): e1-e12. doi: 10.2105/ajph.2017.303818

Giffen, P. J., Endicott, S., and Lambert, S. 1992. Panic and indifference: The politics of Canada's drug laws. Ottawa, ON: Canadian Centre on Substance Abuse. Available at: https://www.worldcat.org/title/ panic-and-indifference-the-politics-of-canadas-drug-laws/oclc/ $1037656092 \&$ referer $=$ brief_results [accessed 18 Jan. 2019].

Goode, E. 1970. The marijuana smokers. New York: Basic Books.

Government of Canada. 2018. Cannabis Act (S.C. 2018, c. 16). Ottawa, ON: Government of Canada. Available at: https://laws-lois.justice. gc.ca/eng/acts/C-24.5/ [accessed 18 Jan. 2019].

Kim, H. S., Hall, K. E., Genco, E. K., Van Dyke, M., Barker, E., and Monte, A. A. 2016. Marijuana tourism and emergency department visits in Colorado. N Engl J Med. 374(8): 797-798. doi: 10.1056/ NEJMc1515009

Kim, K.-H., Jahan, S. A., Kabir, E., and Brown, R. J. C. 2013. A review of airborne polycyclic aromatic hydrocarbons (PAHs) and their human health effects. Environ Int. 60: 71-80. doi: 10.1016/j. envint.2013.07.019

Lovecchio, Fand Heise, C. W. 2015. Accidental pediatric ingestions of medical marijuana: A 4-year poison center experience. Am J Emerg Med. 33(6): 844-845. doi: 10.1016/j.ajem.2015.03.030

Marks, J. 1993. The paradox of prohibition. In C. Brewer (ed.) Treatment options in addiction: Medical management of alcohol and opiate abuse (pp. 77-85). London: Gaskell.

Meade, L., Hoerl, A., and Franklin, P. (Writers) and L. J. Gasnier (Director). (1936). Reefer madness. Los Angeles, CA: Grand National Studios, George A. Hirliman Productions.

National Academies of Sciences Engineering and Medicine. 2017. The health effects of cannabis and cannabinoids: The current state of evidence and recommendations for research. Washington, DC: The National Academies Press. Available at: https://www.nap.edu/ catalog/24625/the-health-effects-of-cannabis-and-cannabinoids-thecurrent-state [accessed 18 Jan. 2019].

Ontario Ministry of Health and Long-term Care. No smoking, no vaping signs for businesses [Official sign name: Controlled areas in certain residential facilities]. [Online] Available at: https://www.ontario.ca/page/no-smoking-no-vaping-signs-businesses [accessed 18 Jan. 2019].

Orens, A., Light, M., Lewandowski, B., Rowberry, J., and Saloga, C. 2018. Market size and demand for marijuana in Colorado. 2017 market update. Denver, CO: Marijuana Policy Group, commissioned by the Colorado Department of Revenue. Available at: https://www.colorado.gov/pacific/sites/default/files/MED\%20 Demand\%20and\%20Market\%20\%20Study\%20\%20082018.pdf [accessed 18 Jan. 2019].

Regional Municipality of Wood Buffalo. Bylaw No. 18/015 - A bylaw of the Regional Municipality of Wood Buffalo to regulate smoking and vaping in public places, work places, and public transportation vehicles and property [no smoking, no vaping sign]. Wood Buffalo: Regional Municipality of Wood Buffalo. Available at: http://www. rmwb.ca/Assets/Departments/Legislative+and+Legal+Services/ Public+Hearings/July+9+2018/6.++Bylaw+18.015+-+Smoking+ and+Vaping+Bylaw.pdf [accessed 18 Jan. 2019].

Reporter, S. 2003. Just say maybe. Economist. 366: (72-73).

Roe, G. 2005. Harm reduction as paradigm: Is better than bad good enough? The origins of harm reduction. Crit Public Health. 15(3): 243-250. doi: 10.1080/09581590500372188

Small, E. 2015. Evolution and classification of cannabis sativa (marijuana, hemp) in relation to human utilization. Bot Rev. 81(3): 189-294. doi: 10.1007/s12229-015-9157-3

StartTalkingNow.org. Home page. Olympia, WA: Washington Health Care Authority. Available at: https://www.starttalkingnow.org/ [accessed 18 Jan. 2019].

Steigerwald, S., Wong, P. O., Khorasani, A., and Keyhani, S. 2018. The form and content of cannabis products in the United States. J Gen Intern Med. 33(9): 1426-1428. doi: 10.1007/s11606-018-4480-0

Steiner, L. 2018. Fact sheet: Environmental health risks of personal cannabis cultivation. Vancouver, BC: National Collaborating Centre for Environmental Health. Available at: http://www.ncceh.ca/documents/guide/fact-sheet-environmental-health-risks-personal-cannabiscultivation [accessed 18 Jan. 2019].

Sullivan, N., Elzinga, S., and Raber, J. C. 2013. Determination of pesticide residues in cannabis smoke. J Toxicol. 2013: 1-6. doi: $10.1155 / 2013 / 378168$

Wang, G. S., Roosevelt, G., Le Lait, M. C., Martinez, E. M., BucherBartelson, B., Bronstein, A. C., and Heard, K. 2014. Association of unintentional pediatric exposures with decriminalization of marijuana in the United States. Ann Emerg Med. 63(6): 684-689. doi: 10.1016/j.annemergmed.2014.01.017

Warf, B. 2014. High points: An historical geography of cannabis. Geogr Rev. 104(4): 414-438. doi: 10.1111/j.1931-0846.2014.12038.x

Whatslegaloregon.com. 2018. Educate before you recreate [fact sheet]. Salem, OR: Whatslegaloregon.com. Available at: http://whatslegaloregon.com/wp-content/uploads/Fact-Sheet_ENG_Nov11.pdf [accessed 18 Jan. 2019]. 